\title{
Sensitivity of Antarctic Circumpolar Current Transport and Eddy Activity to Wind Patterns in the Southern Ocean*
}

\author{
Clothilde E. LANGLAis \\ Oceans and Atmosphere Flagship, Centre for Australian Weather and Climate Research, CSIRO, Hobart, Tasmania, Australia \\ STEPHEN R. RINTOUL \\ Oceans and Atmosphere Flagship, Centre for Australian Weather and Climate Research, CSIRO, and Antarctic Climate \\ and Ecosystems Cooperative Research Centre, University of Tasmania, Hobart, Tasmania, Australia
}

JAN D. ZIKA

University of Southampton, National Oceanography Centre, Southampton, United Kingdom

(Manuscript received 11 March 2014, in final form 12 January 2015)

\begin{abstract}
The Southern Hemisphere westerly winds have intensified in recent decades associated with a positive trend in the southern annular mode (SAM). However, the response of the Antarctic Circumpolar Current (ACC) transport and eddy field to wind forcing remains a topic of debate. This study uses global eddy-permitting ocean circulation models driven with both idealized and realistic wind forcing to explore the response to interannual wind strengthening. The response of the barotropic and baroclinic transports and eddy field of the ACC is found to depend on the spatial pattern of the changes in wind forcing. In isolation, an enhancement of the westerlies over the ACC belt leads to an increase of both barotropic and baroclinic transport within the ACC envelope, with lagged enhancement of the eddy kinetic energy (EKE). In contrast, an increase in wind forcing near Antarctica drives a largely barotropic change in transport along closed $f / H$ contours ("free mode"), with little change in eddy activity. Under realistic forcing, the interplay of the SAM and the El Niño-Southern Oscillation (ENSO) influences the spatial distribution of the wind anomalies, in particular the partition between changes in the wind stress over the ACC and along $f / H$ contours. This study finds that the occurrence of a negative or positive ENSO during a positive SAM can cancel or double the wind anomalies near Antarctica, altering the response of the ACC and its eddy field. While a negative ENSO and positive SAM favors an increase in EKE, a positive ENSO and positive SAM lead to barotropic transport changes and no eddy response.
\end{abstract}

\section{Introduction}

In the Southern Ocean (SO), the southward shoaling of isopycnals supports the deep-reaching geostrophic Antarctic Circumpolar Current (ACC) (Rintoul et al. 2001). The mean state and variability of the isopycnals slope are controlled by the large-scale wind forcing,

\footnotetext{
* Supplemental information related to this paper is available at the Journals Online website: http://dx.doi.org/10.1175/JPO-D-14-0053.s1.

Corresponding author address: Clothilde E. Langlais, Centre for Australian Weather and Climate Research, CSIRO, Oceans and Atmosphere Flagship, Castray Esplanade, Hobart, TAS, 7000, Australia.

E-mail: clothilde.langlais@gmail.com
}

buoyancy forcing, and the interaction of eddies with the mean flow. The westerly winds contribute to increasing the tilt of the isopycnals through northward Ekman transport and the associated deep geostrophic return flow (below the sill depth), accelerating the ACC (Marshall and Radko 2003). Both local and remote buoyancy forcing also play a role in the setup and modification of the density structure (Gnanadesikan and Hallberg 2000; Gent et al. 2001; Hallberg and Gnanadesikan 2001). Transient and standing eddies are the main mechanisms that transfer momentum downward (Rintoul et al. 2001), flattening the isopycnals and acting as a brake for the ACC. Instability of the ACC fronts maintains the high levels of eddy activity in the Southern Ocean. Numerous theoretical and modeling studies have advanced our understanding of these three 
main mechanisms (Stevens and Ivchenko 1997; Marshall and Radko 2003; Olbers et al. 2004; Olbers and Visbeck 2005; Hallberg and Gnanadesikan 2001, 2006; Treguier et al. 2007; Farneti et al. 2010; Dufour et al. 2012) [see Rintoul et al. (2001), Saenko (2007), and Rintoul and Naveira Garabato (2013) for reviews on the subject]. However, a complete understanding of how they together set the strength of the ACC transport is lacking.

This baroclinic view of the ACC mainly focuses on the role of the density structure in the Southern Ocean. However, the baroclinic transport is not the only contribution to the ACC transport. The barotropic current and wind-driven Ekman flow near the surface also contribute to the ACC transport. Moreover, this baroclinic view of the ACC is derived from arguments purely based on the zonal momentum balance (depthintegrated momentum equation). Alternative theories based on the barotropic vorticity balance (depthintegrated vorticity equation) have also been developed (Hughes et al. 1999; Zika et al. 2013b). The integral of the depth-integrated vorticity balance along an $\mathrm{f} / \mathrm{H}$ contour that forms a closed loop around Antarctica relates the line integral of wind stress to acceleration of the depth-averaged flow along the contour. This acceleration would persist in the absence of friction and changes in potential energy [see Eq. (5) in Zika et al. 2013b]. This unconstrained "free-mode" has been proposed as a possible mechanism for setting the transport of the southern part of the ACC, where $f / H$ contours loop around Antarctica. Wind stress along circumpolar $f / H$ contours close to Antarctica is correlated at near-zero time lag (less than 10 days) with the total circumpolar transport (Hughes et al. 1999). The near-instantaneous response of the flow is due to the fast propagation of barotropic waves (Webb and DeCuevas 2007). More recently, Zika et al. (2013b) revisited this idea using sensitivity experiments. They suggested that the total circumpolar transport is composed of a "momentum balance" contribution and a "free-mode" contribution, the transport being sensitive to a linear combination of the wind stress over the ACC envelope and the wind stress along the coast of Antarctica. These studies suggest it is necessary to distinguish between the transport carried by the ACC envelope composed of strong eastward ACC jets and the total circumpolar transport defined as the transport between Antarctica and the continents to the north. The ACC transport and total circumpolar transport will differ in magnitude and in their response to changes in forcing.

The westerly winds have intensified and shifted poleward during recent decades, reflecting an intensification of the southern annular mode (SAM) (Thompson and Solomon 2002; Marshall 2003). The response of the ACC transport and eddy activity to change in wind forcing remains a topic of debate. The wind intensification could lead to an acceleration of the circulation or intensification of the eddy activity, with potential implications for heat and carbon transport. In the linear theory, the ACC transport varies linearly with the wind stress over the ACC envelope (Gnanadesikan and Hallberg 2000; Tansley and Marshall 2001; Marshall 2003; Saenko et al. 2005; Fyfe and Saenko 2006). Eddies remain invariant under increasing wind stress, and stronger wind forcing leads to enhanced transport. Alternatively, in the idealized eddy saturation response, increasing wind is balanced by an enhanced eddy field, without altering the ACC transport (Straub 1993). Some modeling studies revealed an ocean state close to the eddy saturation regime, with weak response of the transport to wind perturbations (Meredith and Hogg 2006; Hallberg and Gnanadesikan 2001, 2006; Screen et al. 2009; Morrow et al. 2010; Farneti et al. 2010). Similarly, the observation of a relative invariance of the ACC transport under variable wind forcing (at interannual or longer time scales) has been attributed to partial eddy saturation (Meredith et al. 2004; Böning et al. 2008). In both the acceleration and eddy saturation limits, eddies act to partially balance the wind. Recent studies (Hallberg and Gnanadesikan 2006; Farneti et al. 2010; Meredith et al. 2012; Dufour et al. 2012; Morrison and Hogg 2013) suggest the ACC response sits between these two limits, with significant but partial eddy saturation and a weak increase in transport in response to increasing winds. Hall and Visbeck (2002) and Sen Gupta and England (2007) found that the transport increase in response to SAM was mainly because of changes in the zonal barotropic current and wind-driven Ekman flow near the surface rather than changes in the density structure.

In the eddy saturation regime, the change in eddy activity has been attributed to change in baroclinic activity. Strengthened winds lead to enhanced northward Ekman transport, which increases the tilt of the isopycnals and so increases the available potential energy (APE; the portion of the potential energy that is available for the conversion into kinetic energy). The enhanced APE then cascades to eddy kinetic energy (EKE) through baroclinic instability. The eddy response lasts until eddies flatten the isopycnal slopes back to their initial values. In this scenario, the eddy activity counterbalances the temporarily enhanced tilt and maintains the density structure.

In this paper, we use both eddy-permitting and eddyresolving ocean general circulation models (OGCMs) to explore the dynamical response of the ACC to realistic wind forcing at interannual time scales. In particular, we focus on the role of two wind-forcing terms, wind stress over the ACC envelope and wind stress around Antarctica, 
TABLE 1 . Summary of attributes of the ocean simulations. The ORCA025 simulations are based on NEMO and OFAM simulations are based on MOM. BRAN uses data assimilation.

\begin{tabular}{|c|c|c|c|c|c|c|c|}
\hline Grid & Run & Resolution & Forcing & Period used & $\begin{array}{c}\text { Initial } \\
\text { Condition }\end{array}$ & $\begin{array}{l}\text { Ocean } \\
\text { model }\end{array}$ & Reference \\
\hline \multirow[t]{4}{*}{ ORCA025 } & ORCA025-G70 & Global $1 / 4^{\circ}$ & Reanalysis DFS3 & 1985-2007 & Climatology & NEMO & $\begin{array}{c}\text { Barnier et al. } \\
\text { (2009) and } \\
\text { this study }\end{array}$ \\
\hline & NY-REF & Global $1 / 4^{\circ}$ & Normal year CORE2 & $10 \mathrm{yr}$ & Climatology & NEMO & $\begin{array}{l}\text { Zika et al. } \\
\text { (2013b) and } \\
\text { this study }\end{array}$ \\
\hline & NY-WIND & Global $1 / 4^{\circ}$ & $\begin{array}{l}\text { Normal year } \\
\text { CORE2 + increased } \\
\text { westerlies }\end{array}$ & $4.5 \mathrm{yr}$ & NY-REF & NEMO & $\begin{array}{l}\text { Zika et al. } \\
\text { (2013b) and } \\
\text { this study }\end{array}$ \\
\hline & NY-ANT & Global $1 / 4^{\circ}$ & $\begin{array}{l}\text { Normal year } \\
\text { CORE2 + decreased } \\
\text { easterlies }\end{array}$ & $4 \mathrm{yr}$ & NY-REF & NEMO & $\begin{array}{l}\text { Zika et al. } \\
\text { (2013b) and } \\
\text { this study }\end{array}$ \\
\hline \multirow[t]{3}{*}{ OFAM } & OFAM2 & $\begin{array}{l}1 / 10^{\circ} \text { in } \\
\text { Australasia } \\
\text { sector }\end{array}$ & $\begin{array}{l}\text { Reanalysis } \\
\text { ERA-40 fluxes }\end{array}$ & 1993-2006 & Climatology & MOM4 & $\begin{array}{l}\text { Schiller } \\
\quad \text { et al. (2008) }\end{array}$ \\
\hline & BRAN & $\begin{array}{l}1 / 10^{\circ} \text { in } \\
\text { Australasia } \\
\text { sector }\end{array}$ & $\begin{array}{l}\text { Reanalysis } \\
\text { ERA-40 fluxes }\end{array}$ & 1993-2006 & OFAM2 & $\begin{array}{l}\text { MOM4 data } \\
\text { assimilation }\end{array}$ & Oke et al. (2008) \\
\hline & OFAM3 & Global $1 / 10^{\circ}$ & $\begin{array}{l}\text { Reanalysis } \\
\text { ERA-Interim fluxes }\end{array}$ & 1993-2007 & Climatology & MOM4 & Oke et al. (2013) \\
\hline
\end{tabular}

in setting the total circumpolar transport and mesoscale eddy field. We identify two different responses to changes in wind: a barotropic acceleration response and a baroclinic eddy saturation response. We investigate the potential causes of the different responses of the ocean to wind-strengthening events, focusing on the role of the baroclinic and barotropic driving mechanisms of the ACC.

The outline of this paper is as follows: The ocean models and the different experiments are described in section 2, along with a discussion of the models' ability to represent the variability of the EKE and ACC transport. In section 3, we analyze the ACC responses to wind forcing. We first use sensitivity experiments to better understand the baroclinic and barotropic characteristics of the ocean response to two idealized wind forcings: wind stress over the ACC envelope and wind stress around Antarctica. We then analyze the ocean response to realistic wind forcing during the 1985-2007 period. In section 4 , we relate the different wind-forcing terms to the interplay of the two dominant modes of atmospheric variability: SAM and the extratropical signature of the El Niño-Southern Oscillation (ENSO).

\section{Data and methods}

\section{a. Ocean model configurations}

A summary of the attributes of the ocean simulations can be found in Table 1 .

\section{1) ORCA025 SIMULATIONS}

We use the ORCA025-G70 (hereinafter ORCA025) global ocean and sea ice simulation implemented and performed by the DRAKKAR group (Barnier et al. 2007; Barnier et al. 2009; Penduff et al. 2007; Penduff et al. 2010). The model configuration is based on the Nucleus for European Modeling of the Ocean (NEMO) code (Madec 2008). The resolution is $1 / 4^{\circ}$ at the equator with a variation of the meridional scale factor as cosine of the latitude, giving a horizontal resolution of $11.7 \mathrm{~km}$ at $65^{\circ} \mathrm{S}$ and $19.6 \mathrm{~km}$ at $45^{\circ} \mathrm{S}$. The vertical resolution varies from $6 \mathrm{~m}$ near the surface to $250 \mathrm{~m}$ at $5750 \mathrm{~m}$, with a total of 46 vertical levels. The air-sea fluxes are derived from bulk formulae. The interannual atmosphericforcing dataset, called DRAKKAR forcing set 3 (DFS3) (Brodeau et al. 2010), is constructed using the CORE forcing (Large and Yeager 2009) and data from the ERA-40 reanalysis (Kallberg et al. 2004) for the period 1958-2000 and the ECMWF analysis for the period 2000-07. No parameterization of eddy diffusion (e.g., Gent and McWilliams 1990; GM parameterization hereinafter) is employed in the simulation and no restoring is applied at depth.

We also use sensitivity experiments performed with ORCA025 with 75 levels (Zika et al. 2013b). A reference normal year experiment (NY-REF) was run for $16 \mathrm{yr}$ using "CORE1 normal year forcing" repeated each year (Griffies et al.2009). Anomalous wind patterns were then added on top of the normal year forcing to produce two 
sensitivity experiments. In the normal year plus ACC wind experiment (NY-WIND), the anomalous wind is a reinforcement of the westerlies over the ACC $(30 \%$ increase of the eastward part of the annual-mean zonal winds between $30^{\circ}$ and $68^{\circ} \mathrm{S}$ ). In the normal year plus Antarctica wind experiment (NY-ANT), the anomalous wind involves switching off the easterlies around Antarctica (removing the westward part of the annual-mean zonal wind south of $40^{\circ} \mathrm{S}$ ). Changes in the wind induce changes in heat fluxes due to the use of bulk formulae. The anomalous wind patterns are applied for $1 \mathrm{yr}$ after which the normal year forcing is reestablished.

\section{2) OFAM SIMULATIONS}

We also use two configurations of the Ocean Forecasting Australia Model (OFAM) simulations based on version $4 \mathrm{p} 0$ of the Modular Ocean Model (MOM4; Griffies 2004). The first configuration has a resolution of $1 / 10^{\circ}$ in the Asian-Australian region $\left(90^{\circ}-180^{\circ} \mathrm{E}\right.$, south of $17^{\circ} \mathrm{N}$ ), giving a resolution of $4.7 \mathrm{~km}$ at $65^{\circ} \mathrm{S}$ to $7.8 \mathrm{~km}$ at $45^{\circ} \mathrm{S}$ and a constant meridional resolution of $11 \mathrm{~km}$. Outside this domain, the horizontal resolution decreases progressively to $1^{\circ}$ across the Indian and Pacific Oceans and $2^{\circ}$ in the Atlantic Ocean. This grid has 47 vertical levels, with $10-\mathrm{m}$ resolution to $200-\mathrm{m}$ depth and 35 levels in the top $1000 \mathrm{~m}$. We use two simulations run with this configuration: a free run (referred to here as the OFAM2 free run) and a multiyear reanalysis with data assimilation [Bluelink Reanalysis (BRAN)] (Schiller et al. 2008; Oke et al. 2008; Langlais et al. 2011). Both simulations are integrated from 1992 to 2006 and forced with interannual 6-hourly surface fluxes. From 1992 to mid-2002, wind stress, heat, and freshwater fluxes are provided by the ERA-40 reanalysis and from mid-2002 until 2006 by the ECMWF forecast. The second configuration is the $1 / 10^{\circ}$ global version of OFAM (called OFAM3) (Oke et al. 2013). The free run is integrated from 1992 to 2011 and forced with interannual 6-h surface fluxes provided by ERA-Interim (Dee et al. 2011). In those three simulations, no GM parameterization is employed, and a 1-yr restoration toward the climatology is applied below $2000 \mathrm{~m}$.

\section{b. Interannual zonal wind stress variability}

During our study period (from 1985 to 2007), the different atmospheric-forcing sets [i.e., ERA-40ECMWF fluxes for OFAM2 and BRAN, fluxes calculated with ERA-40-ECMWF parameters (DFS3) for ORCA025 and ERA-Interim fluxes for OFAM3] provide similar zonal wind stresses in the Southern Ocean (averaged between $40^{\circ}$ and $70^{\circ} \mathrm{S}$ ), with three windstrengthening events in 1989/90, 1993, and 1998/99 represented in the three forcing sets and a fourth one only represented by ECMWF in 2004 (Fig. 1, upper panel thin lines). In all forcing sets, those wind reinforcements mainly occur over the ACC envelope (for clarity, the ACC average is only shown for ORCA025 in Fig. 1). Defining SAM as the first empirical orthogonal function (EOF) of the zonal wind stress, the wind-strengthening events over the ACC correspond to the positive phase of SAM (Fig. 1b), whose spatial pattern is characterized by a southward shift of the wind maximum and a reinforcement around $60^{\circ} \mathrm{S}$ (Fig. 1c). The wind forcings provided by ERA-40 and ERA-Interim give similar results in term of spatial patterns and temporal variability of SAM. However, ERA-Interim shows stronger wind stress amplitude (associated with SAM) than ERA-40.

One of the difficulties of analyzing the oceanic response to each individual wind-strengthening event is that the response does not reach a steady state; the ocean is constantly disturbed and it can be difficult to isolate the response. During our studied period, the positive SAM events are approximately $4 \mathrm{yr}$ apart, so we are only able to isolate the individual response to each event in this window. Another difficulty is that SAM does not completely explain the wind variability. In 2001/02, a positive anomaly of zonal wind stress occurs that does not correspond to a positive SAM event. The positive anomaly does not show an annular pattern; the strengthening only occurs in the Atlantic and western Indian sectors (from $70^{\circ} \mathrm{W}$ to $60^{\circ} \mathrm{E}$ ) (not shown). It is also interesting to note that the wind stress anomalies associated with SAM are an order of magnitude smaller than the mean wind.

\section{c. Ocean variability}

The four high-resolution simulations (ORCA025, BRAN, OFAM2, and OFAM3) have a good representation of the frontal structure and filamented nature of the ACC and show spatial patterns of EKE that are consistent with altimetric observations (Langlais et al. 2011) (Fig. 2). The models' resolution is sufficient to capture much of the mesoscale variability (deformation radius is 10 to $20 \mathrm{~km}$ in the Southern Ocean) and resolve the development of baroclinic eddies. For OFAM2 and BRAN simulations, we restrict the EKE analysis to the high-resolution sector between $105^{\circ}$ and $175^{\circ} \mathrm{E}$.

The gradual loss of volume of Antarctic Bottom Water in ORCA025 (which does not form enough Antarctic Bottom Water; Zika et al. 2013a) coincides with a downward drift in the ACC transport (Treguier et al. 2010; Dufour et al. 2012). This model drift is associated with an EKE drift, consistent with a decrease in baroclinic instability (because of the decrease of the density gradient across the ACC). We apply a linear fit 

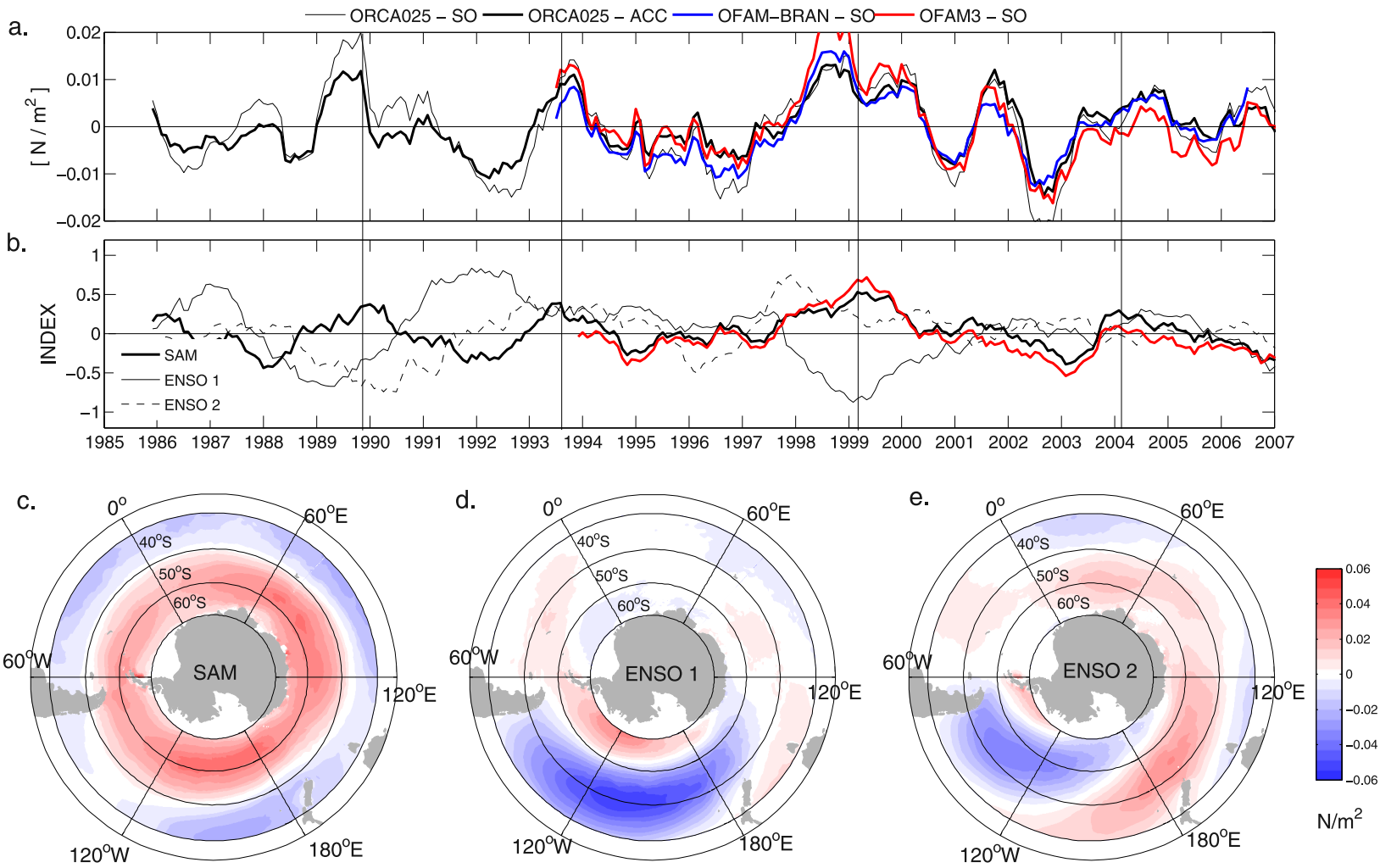

FIG. 1. Zonal wind stress EOF analysis: (a) time series of the zonal wind stress anomalies $\left(\mathrm{N} \mathrm{m}^{-2}\right)$ averaged inside the ACC envelope for ORCA025 (bold black line) and in the Southern Ocean (averaged between $40^{\circ}$ and $70^{\circ} \mathrm{S}$ ) for ORCA025 (thin black line), OFAM2-BRAN (blue line), and OFAM3 (red line); (b) time series of the SAM index [principal component (PC) of the first EOF of the zonal wind] for ORCA025 (bold black lines), OFAM3 (red lines), and ENSO indices (PCs of the second and third EOFs, thin lines) for ORCA025 (the PCs have been normalized to unit variance). The four main positive SAM events are highlighted with vertical lines in (a) and (b). (c),(d), (e) Regressions of the first three PCs on the zonal wind stress in the SO for ORCA025. The resulting maps have the sign and dimensional amplitude $\left(\mathrm{N} \mathrm{m}^{-2}\right)$ of the zonal wind stress (anomalies resulting from one standard deviation increase in the indices).

with a break point in 2000 (when the forcing dataset changes) to remove the long-term trend from the time series. In the OFAM simulations, deep layers are relaxed to the climatology, hence no ACC transport drift nor EKE drift are associated with the lack of formation of bottom water.

\section{d. Methodology}

To investigate the oceanic response to wind-strengthening events, we follow the evolution of the EKE anomaly with respect to the time mean inside the ACC envelope at $100 \mathrm{~m}$ and the zonal transport from land to land at $70^{\circ} \mathrm{W}$ (Drake Passage) and at $168^{\circ} \mathrm{E}$ (south of New Zealand) (Fig. 6). Monthly SSH contours are used to follow the ACC envelope, using the method developed in Langlais et al. (2011). SSH contours -1.02 and $-0.16 \mathrm{~m}$ are used for ORCA025 (Fig. 2). EKE is calculated using velocity anomalies from the monthly average.

The free mode has been proposed as a possible mechanism for setting the southern part of the circumpolar transport where $f / H$ contours are closed (Hughes et al.
1999). For this reason, we divide the circumpolar transport into southern and northern contributions. We arbitrarily define the southern contribution as the transport south of the ACC envelope, that is, between the southern SSH contour and the land. The northern contribution coincides with the main circumpolar ACC jets. The southern contribution coincides with slope currents, recirculation gyres, and eastward jets that are weaker than the main ACC jets (Fig. 2).

To further investigate the baroclinic response, we also calculate the APE and divide the transport into barotropic and baroclinic contributions. We use the local formulation of APE with a linear stratification approximation (Gill 1982; Kang and Fringer 2010):

$$
\mathrm{APE}=-g \int_{z} \frac{\left(\sigma-\bar{\sigma}^{z}\right)^{2}}{2 \partial \bar{\sigma}_{z} / \partial z} d z,
$$

where $\bar{\sigma}_{z}$ is the time-mean density for the entire period at depth $z$. We note that using this approximation, change in the tilt of isopycnals is not the only factor that 


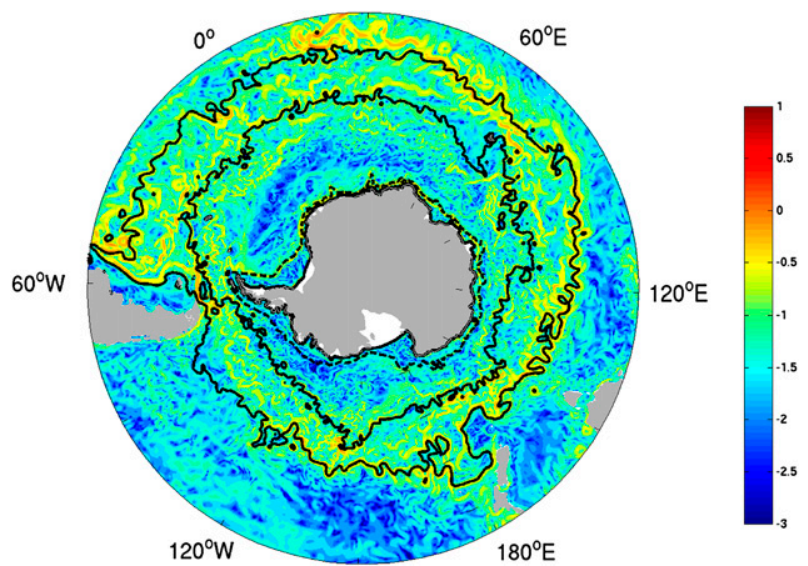

FIG. 2. $\log _{10}$ of magnitude of velocity $\left(\mathrm{m} \mathrm{s}^{-1}\right)$ averaged over the top $100 \mathrm{~m}$ for a monthly mean of ORCA025. The ACC envelope is approximated by two SSH contours $(-1.02$ and $-0.16 \mathrm{~m}$ ) (solid lines). The southern contour is used to distinguish between the transport of the ACC to the north and the southern mode to the south. The circumpolar $f / H$ contour $-4 \times 10^{-8} \mathrm{~s}^{-1} \mathrm{~m}^{-1}$ close to Antarctica is indicated by the dashed line.

could influence changes in APE. Eddies and modification of water masses would also induce APE variability. APE variability is then only used as a broad indication of baroclinic instability.

To divide the transport into barotropic and baroclinic contributions, we use a two-layer model approximation. In this study, the barotropic transport is defined as the transport associated with the velocity of the bottom layer (the averaged velocity in the bottom layer multiplied by the ocean depth). The baroclinic transport is then defined as the difference in transport between the upper and lower layers. This contribution represents the shear between the two layers. Three different boundaries are used to separate the upper and lower ocean layers: 989, 1470, and $2054 \mathrm{~m}$. The resulting transport anomalies are not sensitive to the choice of boundary. As the interaction of the ACC with topography strongly constrains the current's vertical structure, the baroclinic transport response to wind forcing has to be analyzed away from topographic obstacles and is then only shown for the transport south of New Zealand.

\section{Response to wind-strengthening events} a. Sensitivity experiments: Winds over the ACC
envelope versus winds around Antarctica

\section{1) TRANSPORT AND EKE RESPONSES}

We first analyze the oceanic response to a typical strengthening of the westerly winds, comparing NY-WIND and NY-REF. ORCA025's oceanic response to the 1-yr westerly wind increase of $0.05 \mathrm{~N} \mathrm{~m}^{-2}$ shows a simultaneous transport increase of 7.6 Sverdrups $(\mathrm{Sv} ; 1 \mathrm{~Sv} \equiv$ $10^{6} \mathrm{~m}^{3} \mathrm{~s}^{-1}$ ) south of New Zealand, corresponding to 1.3 standard deviations of the NY-REF transport time series (Figs. 3a,b). A transport increase of $5.4 \mathrm{~Sv}$ is also found at Drake Passage (not shown). The EKE response inside the ACC envelope has both an instantaneous as well as a 2-yr lagged increase (Figs. 3c,d). The lagged response accounts for a $16 \%$ increase in EKE as compared to the mean EKE in NY-REF. This EKE response is similar to the delayed eddy response observed and modeled using a quasigeostrophic model that was close to an eddy saturation regime (Meredith and Hogg 2006; Hogg et al. 2008). When the easterlies are turned off along the Antarctica coast (NY-ANT), the total circumpolar transport increases by $4.1 \mathrm{~Sv}$ at Drake Passage and by $4.7 \mathrm{~Sv}$ south of New Zealand, corresponding to 0.8 standard deviations of the NY-REF transport time series. But there is no instantaneous or lagged EKE response inside the ACC envelope (Fig. 3) or close to Antarctica (not shown). The response to wind increase around Antarctica is what we describe as an acceleration response. While both wind stress over the ACC envelope and wind stress along the coast of Antarctica induce an increase in total circumpolar transport, only the wind forcing over the ACC induces an eddy response.

\section{2) ACC JETS VERSUS SOUTHERN TRANSPORT}

The wind stress over the ACC envelope and wind stress along the coast of Antarctica accelerate the flow at different latitudes. The wind stress along the coast of Antarctica is linked with the free mode and mainly induces a transport increase south of the ACC envelope (south of $61.5^{\circ} \mathrm{S}$ for south of New Zealand transport) (Fig. 4a). This increase consists of a reduction of the westward countercurrent around Antarctica and an increase in the eastward transport of the jets south of the main ACC jets and corresponds to 0.9 standard deviations of the NY-REF transport time series. A transport increase of the main ACC jets is also observed (Fig. 4b). It accounts for $1 / 3$ of the total transport increase in 2014, but only corresponds to 0.3 standard deviations of the NY-REF transport time series. In contrast, a modification of the wind stress over the ACC increases the transport of the main ACC jets by 1.2 standard deviations of the NY-REF transport time series (Figs. 4a,b). South of the ACC envelope, the small 1-Sv variations in years 0 and 1 for NY-WIND (that correspond to 0.3 standard deviations of the NY-REF time series) are possibly related to some displacement of the flow across the fixed border between the ACC and southern regimes. 

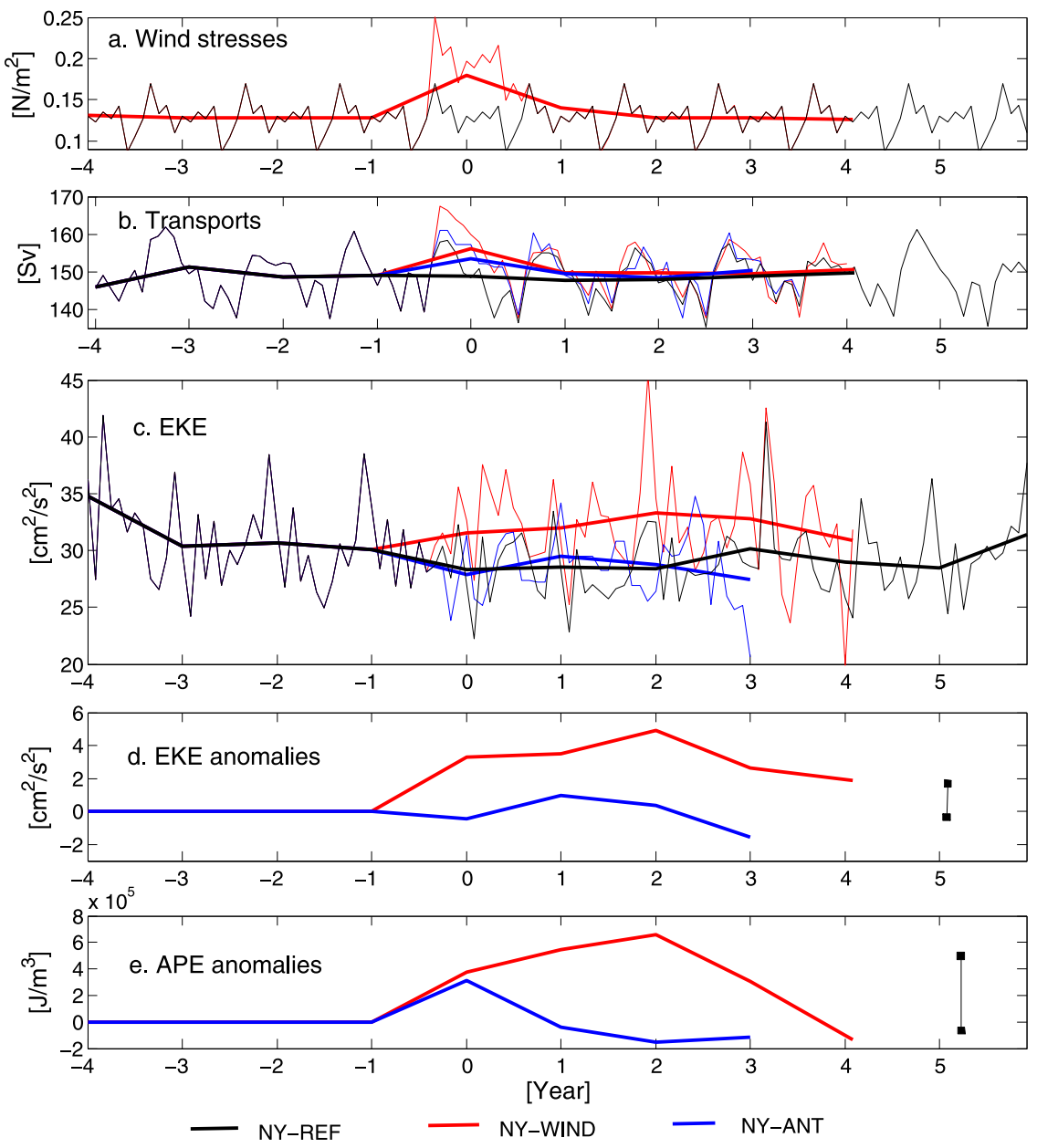

FIG. 3. (a) Monthly (thin lines) and annual (thick lines) zonal wind stresses, (b) transports south of New Zealand, and (c) EKE in NY-REF, NY-WIND, and NY-ANT (black, red and blue lines, respectively). Annual (d) EKE and (e) APE anomalies relative to NY-REF. The vertical line in (d) and (e) show the standard deviation of monthly EKE and APE in NY-REF. Wind stresses, EKE, and APE are averaged inside the ACC envelope identified using SSH contours (Fig. 2).

\section{3) BAROCLINIC RESPONSE: APE AND SHEAR}

We investigate further the origin of the EKE activity in NY-WIND. The EKE response reflects an increase in eddy activity associated with an increase in APE of $6.1 \times$ $10^{5} \mathrm{~J} \mathrm{~m}^{-3}$ in the ACC envelope in comparison with NY-REF (Figs. 3d,e). While this response doubles the amount of APE at year 2, the APE response is not as significant as the EKE response. The standard deviation of the monthly APE time series reaches $6.0 \times 10^{5} \mathrm{~J} \mathrm{~m}^{-3}$ in NY-REF because of strong variability at the 7 to $8 \mathrm{yr}$ time scale. The APE intrinsic variability in NY-REF experiment may reflect water mass changes at decadal time scales and not be only representative of baroclinic instabilities. Nevertheless, APE and EKE evolve similarly, and the APE response is probably an indication of changes in isopycnal slope across the ACC and an enhanced tendency for baroclinic instability. Both EKE and APE show anomalies that persist for $4 \mathrm{yr}$ after the wind anomaly. In contrast, the APE in NY-ANT shows a $50 \%$ increase during the wind anomaly, which corresponds to 0.5 standard deviations of the NY-REF time series and returns to the NY-REF level when the wind anomaly stops. These results support the idea that the free mode drives a barotropic transport increase of the flow, with no change in baroclinic instability properties of the current, while the reinforcement of winds over the ACC envelope enhances baroclinic instabilities that persist until eddies dissipate the additional APE. The response in NY-WIND is consistent with the eddy saturation response described by Meredith and Hogg (2006). To our knowledge, this is the first time a delayed 

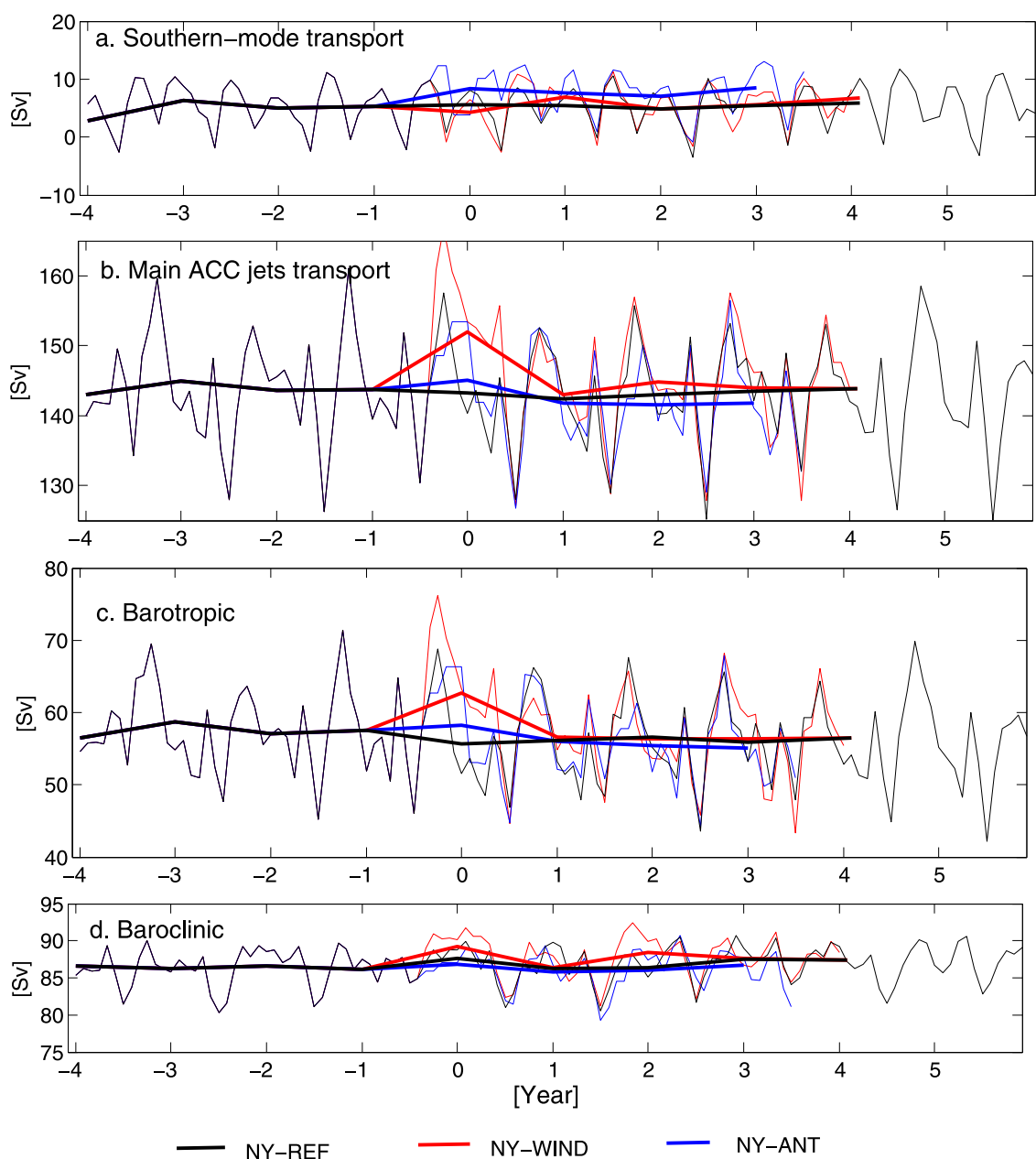

FIG. 4. Monthly (thin lines) and annual (thick lines) transport contributions (Sv) south of New Zealand: (a) southern mode transport (south of $61.5^{\circ} \mathrm{S}$ ), (b) main ACC jets transport (north of $61.5^{\circ} \mathrm{S}$ ), and (c) barotropic and (d) baroclinic contributions to the main ACC jets transport. Transports are presented for NY-REF, NY-WIND, and NY-ANT experiments (black, red, and blue lines, respectively).

EKE response has been demonstrated with a sensitivity experiment in a primitive equation model with realistic topography and the same eddy scales resolved as in Meredith and Hogg (2006).

Isolating the barotropic and baroclinic contributions to the transport changes further clarifies the response of the current to wind changes. The transport increase of the main ACC jets in NY-WIND is a combination of barotropic and baroclinic transport increases (Figs. 4c,d). The barotropic increase is stronger than the baroclinic one. The change in baroclinic transport means that during the wind strengthening, the transport increase in the upper layer is stronger than the increase in the lower layer. This modification of the shear in the transport is consistent with increased APE, increased baroclinic instability, and larger EKE. This increase in the shear only occurs away from topography, as topography largely constrains the vertical structure of the current.

\section{b. Response to interannual wind forcing}

\section{1) ACC TRANSPORT RESPONSES}

In this section, we compare the variability of the ACC transport with those of the two wind-forcing terms that we analyzed with the sensitivity experiments: the wind stress over the ACC and the wind stress along the $f / H$ contour $-4 \times 10^{-8} \mathrm{~s}^{-1} \mathrm{~m}^{-1}$ around Antarctica. For the correlation calculations, the degrees of freedom are calculated as the number of months of the time series divided by 7 minus 2 , as a lag of 7 months is necessary before autocorrelation becomes insignificant.

As found in the sensitivity experiments and in Zika et al. (2013b), the wind stress over the ACC and the wind 
TABLE 2. Correlation coefficients between the total circumpolar transport at Drake Passage and wind forcings in four simulations (ORCA025, OFAM2, BRAN, and OFAM3).

\begin{tabular}{lccc}
\hline \hline & $\begin{array}{c}\text { Linear combination of wind stress over ACC } \\
\text { and along } f / H \text { as in Zika et al. (2013b) }\end{array}$ & $\begin{array}{c}\text { Zonal wind stress } \\
\text { over ACC }\end{array}$ & $\begin{array}{c}\text { Wind stress along } \\
f / H=-4 \times 10^{-8} \mathrm{~s}^{-1} \mathrm{~m}^{-1}\end{array}$ \\
\hline ORCA025 & 0.42 & 0.06 & 0.45 \\
OFAM2 & 0.58 & 0.51 & 0.53 \\
BRAN & 0.48 & 0.51 & 0.42 \\
OFAM3 & 0.62 & 0.18 & 0.63 \\
\hline
\end{tabular}

stress along the $-4 \times 10^{-8} \mathrm{~s}^{-1} \mathrm{~m}^{-1} \mathrm{f} / \mathrm{H}$ contour around Antarctica both drive changes in circumpolar transport in the eddy-permitting simulations presented here. Using the linear relationship between the two wind-forcing terms and the ACC transport found in Zika et al. [2013b, their Eq. (8)], the correlation coefficients between the predicted transport and the simulated transport at Drake Passage are between 0.42 and 0.62 (significant at $99 \%$ for ORCA025, OFAM2, and OFAM3 and $98 \%$ for BRAN) (Table 2). These correlation coefficients are better than when using each wind-forcing term alone, except for BRAN transport where using the wind stress over the ACC alone gives a better correlation.

With realistic interannual wind forcing, it is difficult to isolate the effect of the wind increase over the ACC envelope from wind increase along the $f / H$ contour. For example, the 1990, 1993, and 2004 wind-strengthening events over the ACC also coincide with wind changes close to Antarctica. To try to distinguish the transport responses to each forcing term, we examine the transport variability north and south of the southern limit of the ACC envelope (Fig. 5), $61.5^{\circ} \mathrm{S}$ south of New Zealand (Fig. 2). For ORCA025, the transport of the main ACC jet is significantly correlated with the wind stress over the ACC $(r=0.38$ significant at $95 \%)$, and the southern part of the transport is correlated with the wind stress along the $f / H$ contour $-4 \times 10^{-8} \mathrm{~s}^{-1} \mathrm{~m}^{-1}$ around Antarctica $(r=0.53$ significant at $99 \%)$. These correlation coefficients are larger than when the total circumpolar transport is correlated with each wind-forcing term $(r=$ 0.06 and 0.45 , respectively) (Table 2).

In 1989, 1999, and 2004, the transport increases are mainly because of an increase in the flow of the main ACC jets (Figs. 5a,b). In contrast, the change in transport in 1993 is mainly because of a change in the southern part of the transport: a reduction in the westward-flowing coastal current and increase of the southernmost ACC jets (Figs. 5a,b). An increase in transport of the main ACC jets is still detected but is smaller than the ACC transport increases in 1989 and 1999 (Fig. 5b). Moreover, dividing the transport of the main ACC jets into barotropic and baroclinic components reveals that the 1993 transport increase is solely barotropic (Figs. 5c,d). The
1989 and 1999 wind-strengthening events are the only ones that clearly lead to an increase in baroclinic transport over the ACC (Fig. 5d).

These results support the idea that in 1993 the increase in the circumpolar transport is mainly because of a change in the barotropic free mode. In contrast, in 1989 and 1999 the circumpolar transport increase is mainly driven by wind increases over the ACC and is associated with an increase of both the barotropic and baroclinic flow of the main ACC jets. Under realistic atmospheric forcing, the wind stress over the ACC does not always favor a baroclinic transport. If we apply a linear least squares fit to the two wind-forcing terms, we find a good correlation ( $r=0.56$; significant at $99 \%$ ) with the baroclinic transports (see supplemental information, Fig. S1). This suggests a link between the interplay of the two forcing terms and the baroclinicity.

\section{2) EKE AND BAROCLINIC RESPONSES}

During the 22-yr period, the EKE variability is consistent across the models (during the overlapping period; Fig. 6d). The modeled EKE variability from 1993 to 2007 is consistent with EKE observations (Morrow et al. 2010). The EKE variability from BRAN can be considered as the reference here because the assimilation of satellite sea surface height anomalies reproduces a mesoscale eddy field that is very close to that observed (Oke and Griffin 2011).

With realistic interannual wind forcing, the relationship between EKE and wind stress over the ACC is not as simple as in the sensitivity experiment NY-WIND. As found in Treguier et al. (2010), if we consider the entire record no significant correlation between wind stress over the ACC and EKE or between SAM and EKE is found, even if a time lag is permitted (Fig. 6). However, we find a significant correlation between EKE (Fig. 6d) and the baroclinic transport of the main ACC jets (Fig. 5d), with a maximum correlation of 0.49 significant at $99 \%$ at 30-month lag. The lack of correlation between SAM and EKE comes from the fact that the ACC baroclinicity is not only driven by the intensity of the wind stress over the ACC. Using linear least squares, we can fit the EKE time series to a combination of the wind 


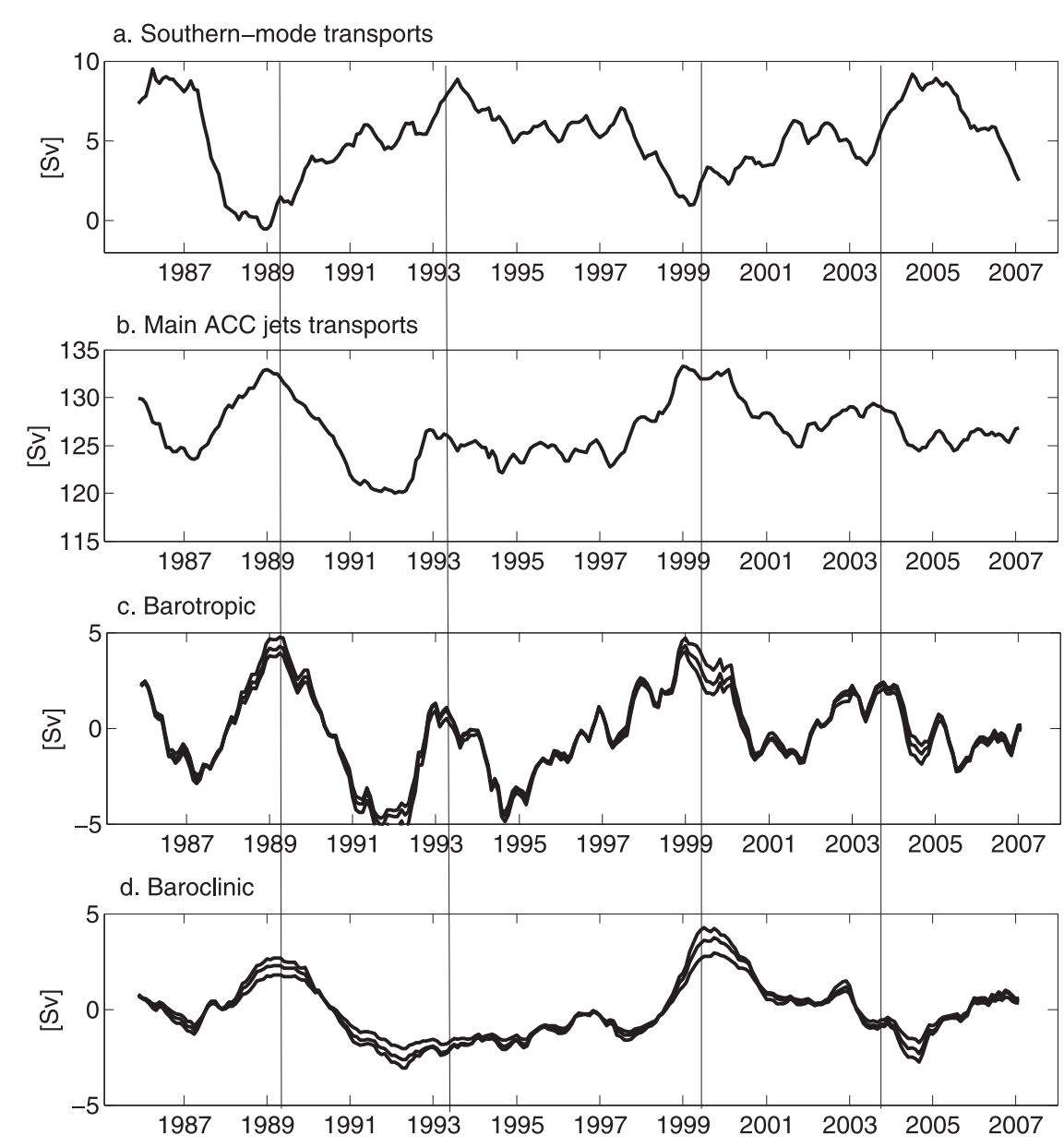

FIG. 5. Transport contributions (Sv) in ORCA025 south of New Zealand: (a) southern mode transports (south of $61.5^{\circ} \mathrm{S}$ ), (b) main ACC jets transport (north of $61.5^{\circ} \mathrm{S}$ ), and (c) barotropic and (d) baroclinic anomalies of the main ACC jets transport south of New Zealand. Barotropic contribution is calculated as the averaged velocity in the lower ocean layer multiplied by the ocean depth, and baroclinic contribution is calculated as the difference between total transport and barotropic transport. In (c) and (d), the three curves correspond to different choices of boundary between upper and lower ocean layers: 989,1470 , and $2054 \mathrm{~m}$. The four main windstrengthening events (positive SAM events) are highlighted with vertical lines.

stress over the ACC and along the $f / H$ contour with a time lag. Using time lags from 20 to 30 months, the correlation coefficients between a combination of the two wind-forcing terms and the EKE range from 0.46 to 0.74 (significant at $99 \%$; Fig. S1). This suggests a link between the interplay of the two forcing terms and the EKE.

Considering each wind-strengthening event individually, three events (in 1989, 1999, and 2004) are followed by an EKE increase 2 to $3 \mathrm{yr}$ after the peak in wind forcing (Fig. 7). The 1993 event is the only one that is not followed by an EKE increase. In 1991/92, 2002, and 2007 the EKE increase is about $18 \%$ of the mean EKE level. The enhanced EKE signal is surface intensified but still detected at $3500 \mathrm{~m}$ (not shown). The EKE bursts in 1991/92 and 2002 follow a buildup of APE over the ACC envelope (Fig. 7), as found in Meredith and Hogg (2006). The weaker 2004 wind event is also associated with an increase in APE but is not a positive anomaly for the period considered. This event is also followed by a positive anomaly in EKE in 2007, although the maximum EKE is smaller than in 1991/92 and 2002. These EKE responses are consistent with the eddy saturation response obtained with the NY-WIND experiment. In contrast, the 1993 wind event is not followed by an increase of APE or EKE.

These results suggest that the 1989 and 1999 windstrengthening events clearly lead to a delayed eddy saturation ocean response. In contrast, the acceleration response in 1993 is largely barotropic. The 1993 event 


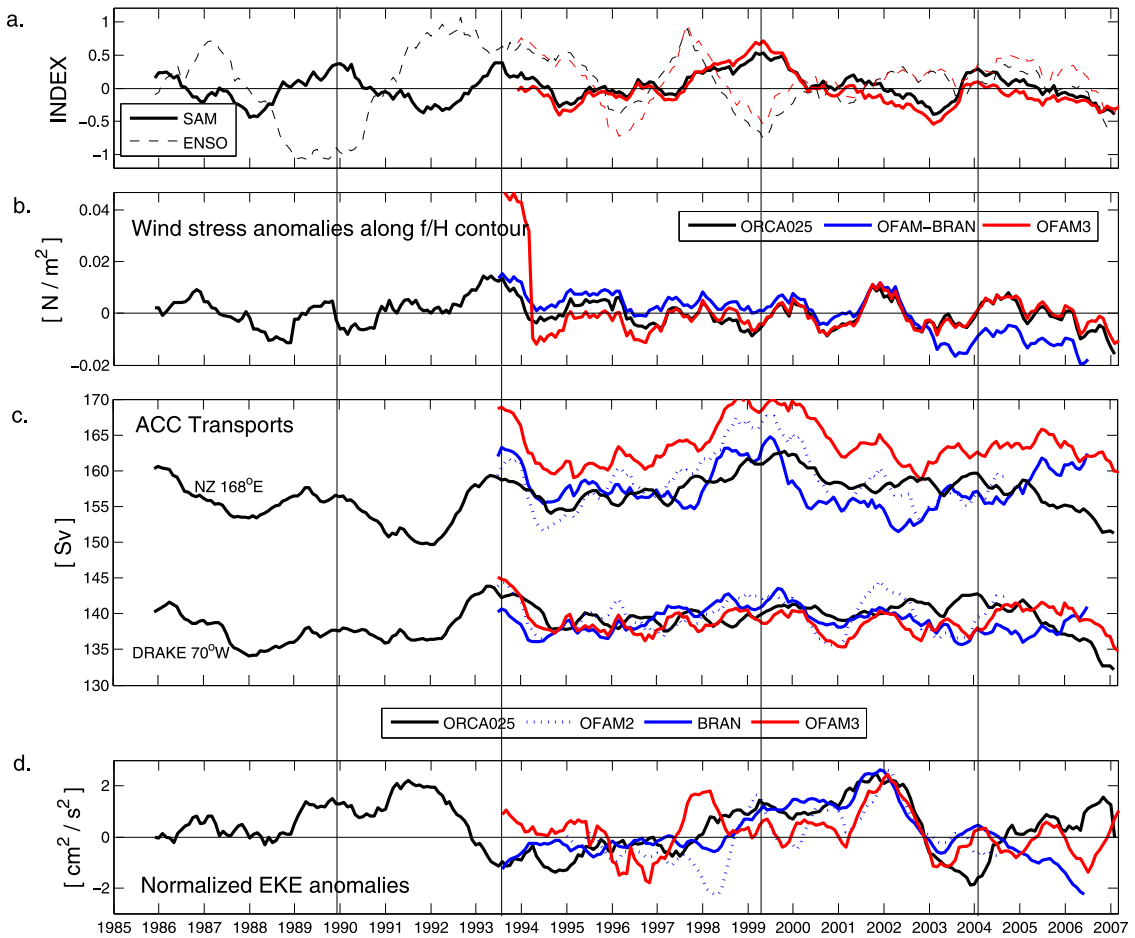

FIG. 6. (a) Time evolution of the climate indices SAM (solid line) and ENSO (dashed lines), (b) anomalies of the wind stress projected along the $\mathrm{f} / \mathrm{H}$ contour equal to $-4 \times 10^{-8} \mathrm{~s}^{-1} \mathrm{~m}^{-1}$, (c) transport at Drake Passage $\left(70^{\circ} \mathrm{W}\right)$ and south of New Zealand $\left(168^{\circ} \mathrm{E}\right)$, and (d) EKE anomalies in the ACC envelope. The four main wind-strengthening events (positive SAM events) are highlighted with vertical lines. The EKE time series have been normalized (divided by the standard deviation of each time series). For easier comparison, the transport time series have been translated so that the mean transports at Drake Passage are all equal to the mean transport of BRAN. Results are shown for ORCA025 (black), OFAM2 (dashed blue), BRAN (blue), and OFAM3 (red). The respective Drake Passage transports are 114, 121, 139, and $152 \mathrm{~Sv}$.

is unique as it coincides with a strong southern mode transport and no baroclinic response of the main ACC jets, despite some wind increase over the ACC envelope.

\section{Interplay of SAM and ENSO}

We next explore the link between the two windforcing terms and the modes of climate variability. The variability of the zonal wind stress in the Southern Ocean is dominated by the first three EOFs (O'Kane et al. 2013). These together explain $62.4 \%$ of the variance with the SAM as the first mode $(33 \%)$ and the extratropical signature of ENSO (propagating in the Southern Hemisphere through atmospheric teleconnections) expressed both in the second and third EOFs $(17.3 \%$ and $12.1 \%$, respectively) (Fig. 1). Interestingly, during our study period two of the positive SAM events (in 1989 and 1999) are out of phase with ENSO (positive ENSO corresponding to an El Niño event), one is in phase with positive ENSO (in 1993), and the last one (2004) is a SAM-only event and is the SAM event with the smallest amplitude during the study period.

While SAM is a good quantifier of the wind variability over the ACC (Thompson and Solomon 2002; Marshall 2003), ENSO can also influence the wind over the ACC (L'Heureux and Thompson 2006; Fogt et al. 2011; Schneider et al. 2012) (Figs. 8a,b). Both modes of climate variability also project onto the wind stress around Antarctica (Figs. 8a,b). Reconstructing the wind-forcing time series using only the first three EOFs of the zonal wind stress (SAM and ENSO), we find that the first three EOFs explain most of the wind stress variability along the $f / H$ contour and over the ACC envelope, with correlation coefficients of 0.85 and 0.84 , respectively. If we use only the first EOF corresponding to SAM, the correlation coefficients drop to 0.54 and 0.80 , respectively. The interplay of SAM and ENSO sets the variability of the two wind-forcing terms that drive the ACC: wind over the ACC and close to Antarctica.

We analyze the impact of potential combinations of SAM and ENSO on the zonal wind stress over the ACC 

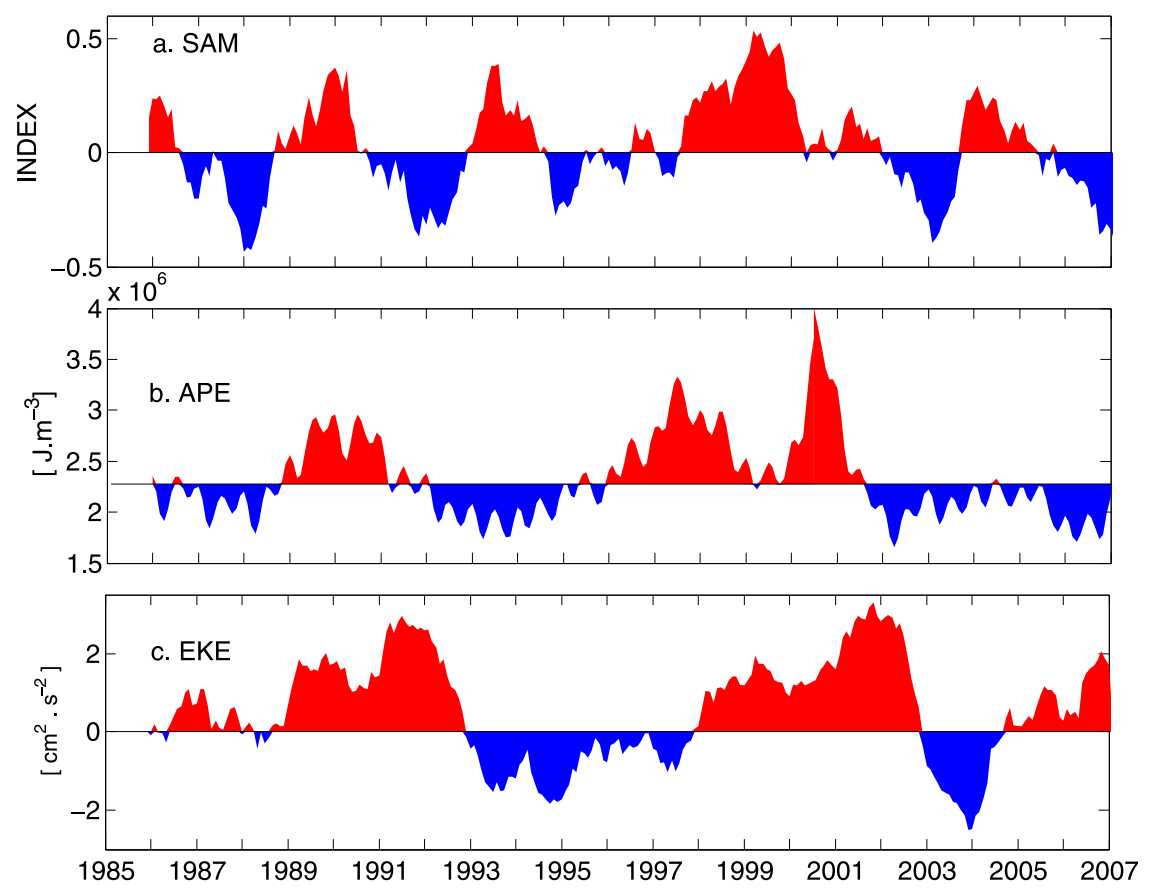

FIG. 7. (a) Time variability of SAM, (b) a measure of the available potential energy, and

(c) EKE anomalies inside the ACC envelope in ORCA025.

envelope and wind stress along the $f / H$ contour. We linearly combined SAM and ENSO EOFs to get all the potential effects of ENSO on SAM annular winds (Fig. 9). In comparison with a positive SAM-only event, the combination of positive SAM and negative ENSO leads to stronger westerlies over the ACC envelope, as reported by others (L'Heureux and Thompson 2006; Fogt et al. 2011; Schneider et al. 2012). Weakening of the westerlies occurs during positive SAM combined with positive ENSO.

Positive phases of SAM and ENSO each induce westerly anomalies close to Antarctica that act to reduce the easterlies (Fig. 9). Negative SAM and ENSO phases produce the opposite effect, reinforcing the easterlies around Antarctica. This interplay is seen in the major wind-strengthening events in the time series. In 1989 and 1999, the combination of a positive SAM and negative ENSO leads to negative and near to zero anomalies of along $f / H$ wind stress. In contrast, in 1993 both positive indices work together and reduce the easterlies. For the wind stress along the $f / H$ contour, the impact of one standard deviation increase of SAM is equivalent to one standard deviation increase of ENSO. However, the impact of $\mathrm{ENSO}$ on the wind stress over the ACC envelope is much smaller than the impact of SAM. ENSO winds have a stronger impact on along $f / H$ wind stress than on the zonal wind stress over the ACC envelope.

The spatial pattern of the wind anomalies are also set by the combination of SAM and ENSO. Wind anomalies during 1989 and 1999 events have similar annular spatial patterns (Fig. 8d; 1989 anomalies are not shown). In comparison with the SAM pattern, the wind-strengthening is associated with an anticyclonic circulation in the Pacific sector, and the wind anomaly occurs over a larger latitudinal extent and has larger amplitude. The 1993 wind-strengthening event shows a less annular pattern with almost no intensification of the wind in the South Pacific but an enhancement of the wind stresses close to Antarctica in the Indo-Pacific sector (Fig. 8c). In 2004, the wind anomalies resemble wind anomalies associated with positive SAM (not shown). The combination of SAM and ENSO explains the differences in the wind patterns. Correlation coefficients between the anomalous spatial patterns (Figs. 8c,d) and their reconstructions using the first three EOFs (Figs. 8e,f) are 0.71, 0.76, and 0.85 for the 1993, 1989, and 1999 wind anomalies, respectively. The correlation coefficients drop to $0.59,0.47$, and 0.18 , when we use only the first EOF for the reconstruction of the anomalous spatial patterns (not shown). The interplay of SAM and ENSO shapes the wind anomalies of the different wind-strengthening events.

\section{Discussion and conclusions}

Models and observations suggest that the ACC is close to an eddy saturation regime (Meredith and Hogg 2006; Böning et al. 2008; Screen et al. 2009; Morrow et al. 2010). However, the evidence is not clear-cut, in part because the eddy saturation is not instantaneous. The 

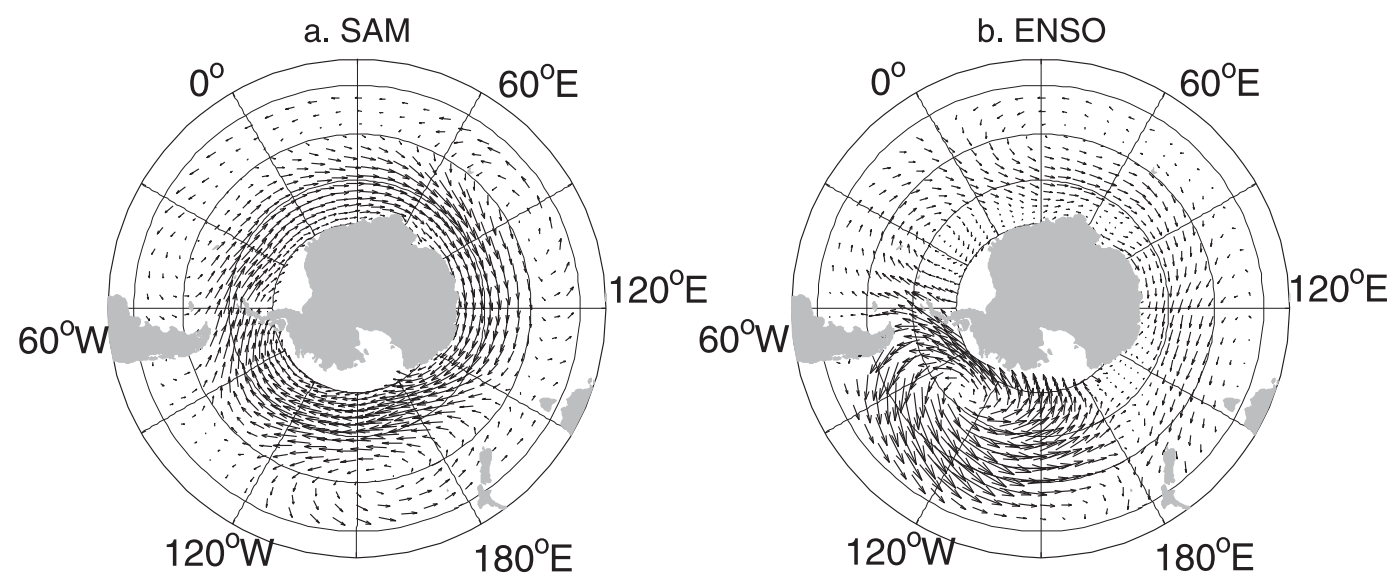

C. 1993 Anomaly
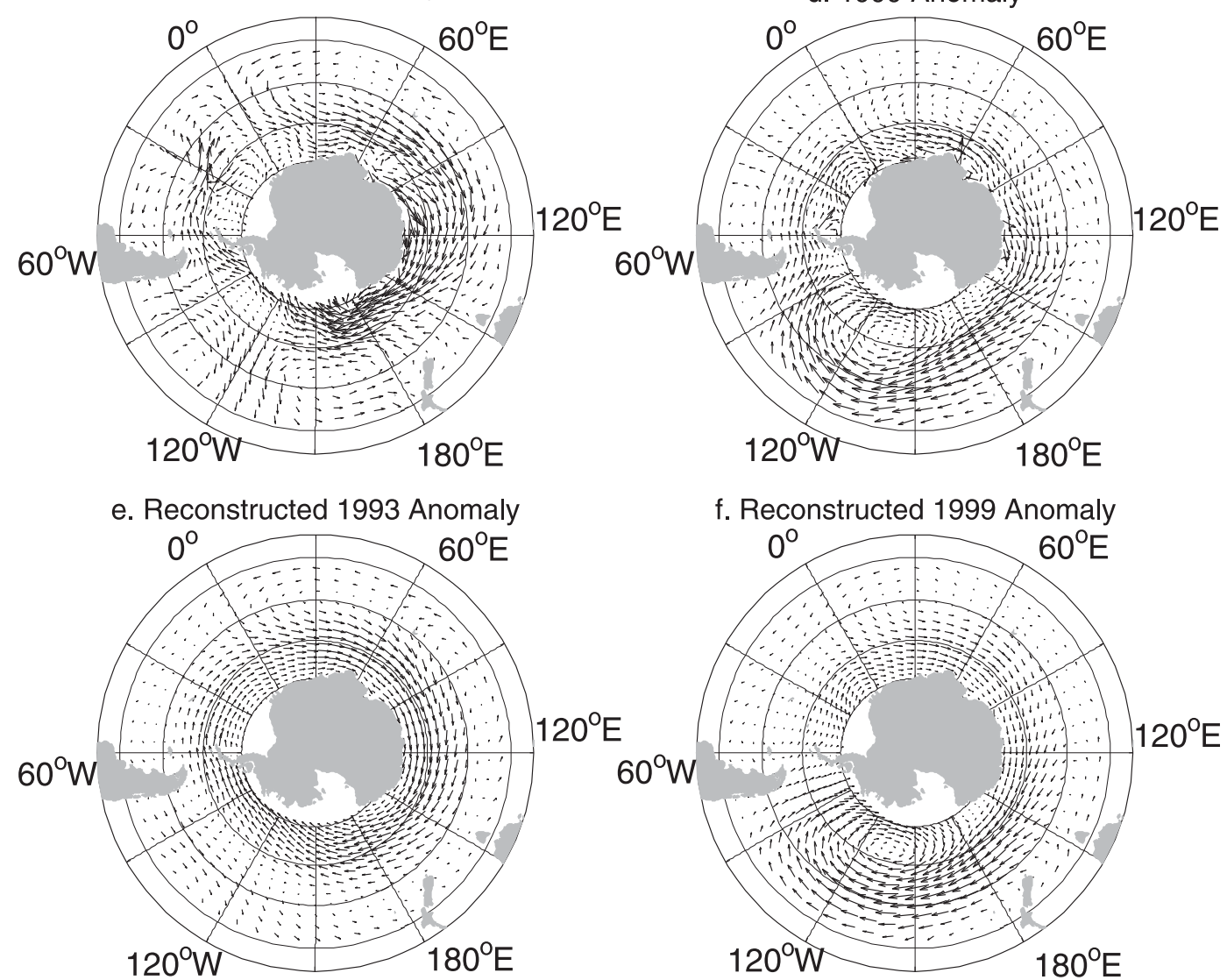

FIG. 8. ORCA025 wind stresses: regression of wind anomalies on the (a) SAM index and (b) ENSO index (anomalies resulting from one standard deviation increase in the indices), anomalies of wind stress during (c) 1993 and (d) 1999 wind-strengthening events, and reconstructed wind stress anomalies in (e) 1993 and (f) 1999 using the first three EOFs of the zonal wind stress.

relationship between EKE and wind variability at interannual time scales is therefore complex. Altimetric observations also show differences in the amplitude of the EKE response to positive SAM events with an intense delayed response in EKE after the 1999 event and low or no response after the 1993 event (Fig. 1 of
Meredith and Hogg 2006; Fig. 2 of Morrow et al. 2010). The time scale at which the eddy mechanisms operate is also important. While at interannual time scales, Treguier et al. (2010) found no clear correlation between EKE and the SAM index in the zonal average; at decadal time scale, their study showed some relationship between the 
a.

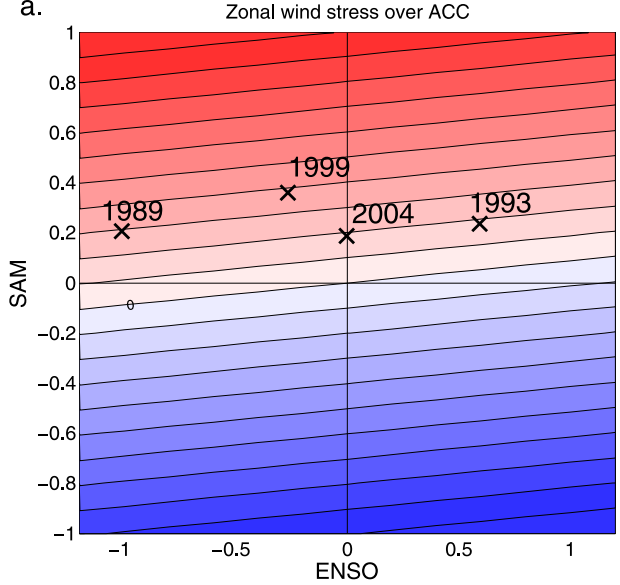

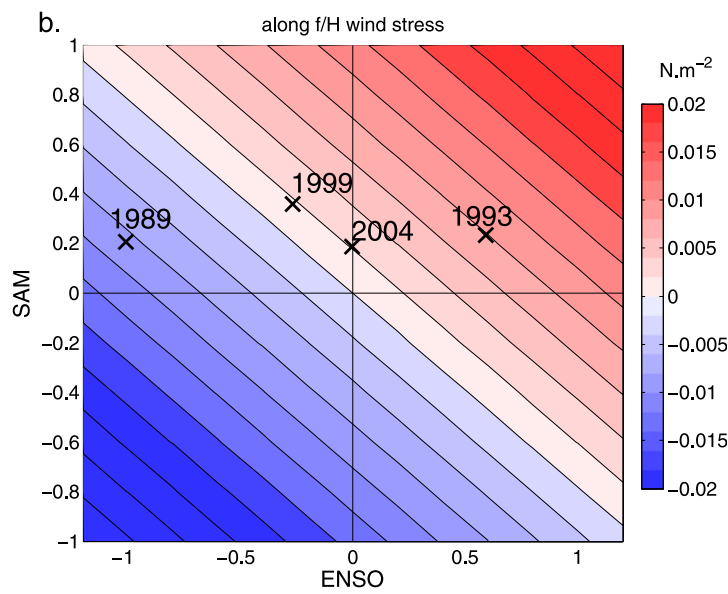

FIG. 9. Contributions of the first three EOFs to the wind stress in the Southern Ocean: (a) zonal wind stress anomalies $\left(\mathrm{N} \mathrm{m}^{-2}\right)$ over the ACC envelope and (b) wind stress anomalies $\left(\mathrm{N} \mathrm{m}^{-2}\right)$ along $\mathrm{f} / \mathrm{H}$ contour equal to $-4 \times$ $10^{-8} \mathrm{~s}^{-1} \mathrm{~m}^{-1}$ near Antarctica generated by linear combinations of SAM and ENSO patterns. The values on the $x$ and $y$ axis correspond to the multiplication coefficients applied to the EOFs that result from one standard deviation increase in the indices. The black crosses and associated year show the four observed SAM/ENSO combinations during our studied period. Red color means stronger wind stress and blue indicates weaker.

weakening of the ACC density structure and decrease of EKE.

Our results show that under realistic atmospheric forcing, increased westerlies do not always favor an increase in eddy activity. We find two distinct responses to wind increases at interannual time scales: delayed eddy saturation-like responses after the 1989, 1999, and 2004 wind-strengthening events and an acceleration-like response during the 1993 wind-strengthening event. The different nature of the response to wind-strengthening events results in a low correlation between wind and EKE. These different responses are linked to different baroclinic and barotropic responses to wind increases and show transport increases at different latitudes. With regard to transport, in 1989 and 1999, the wind increase leads to a transport increase only over the main ACC jets with both barotropic and baroclinic contributions. The 1993 event coincides with a strong barotropic transport south of the ACC envelope and no baroclinic response of the main ACC jets. A barotropic transport increase occurs over the main ACC jets in 1993, but it is smaller than in 1989 and 1999.

Both the latitude and vertical structure of the transport response depends on the spatial pattern of the wind anomaly. We have shown that the transport and EKE response of the ACC depends on the partition between wind stress over the ACC envelope and along $f / H$ contours close to Antarctica, the two important drivers of the ACC transport described in Zika et al. (2013b). The increase of wind stress over the ACC in 1989 and 1999 is stronger than in 1993. In 1993, the westerly wind anomaly is associated with a strong projection of wind anomalies on the $f / H$ contours close to Antarctica, leading to weaker easterly wind around Antarctica. In contrast, there is no change or an increase of the easterly winds in 1989 and 1999.

During the 1993 event, the barotropic transport response close to Antarctica (where $f / H$ contours are closed) reflects the impact of the free-mode mechanism (Hughes et al. 1999). The baroclinic transport responses in 1989 and 1999 reflect the impact of the wind over the ACC. Increases of the barotropic flow over the main ACC jets are due to anomalous sea surface slope during wind-strengthening events and generated via geostrophic adjustment (Fig. S2), as described by Hall and Visbeck (2002) and Sen Gupta and England (2007).

The absence of a baroclinic response of the main ACC jets in 1993 might be linked to two factors. First, as seen in the NY-ANT experiment, wind anomalies on the closed $f / H$ contour around Antarctica drive a barotropic response of the main ACC jets because of changes in sea surface slope. Second, a change in wind does not necessarily result in a change of baroclinicity, as argued in Sallée et al. (2008). Ekman pumping anomalies can intensify or shift the ACC fronts (Sallée et al. 2008). Whether the fronts shift or intensify depends on the relative position of the fronts and the anomalous wind (Sallée et al. 2008). In 1993, positive SAM and ENSO act to shift winds farther south than in 1989 and 1999 (Fig. S3). Ekman pumping near the fronts in 1989 and 1999 may have contributed to an increase in isopycnal tilt, while the stronger southward shift in 1993 may have shifted the fronts to the south with little change in baroclinicity. 
Complete eddy saturation (Straub 1993) implies no acceleration of the zonal transport when comparing two statistically steady states. Our results highlight the transient adjustment period during which the eddy mechanisms operate. Interestingly, the ocean response to wind increase is not purely baroclinic during the adjustment. A barotropic increase of the transport over the main ACC jets occurs systematically during all wind-strengthening events and is stronger than the baroclinic increase. This combination of barotropic and baroclinic response to wind forcing is consistent with results obtained by Sen Gupta and England (2007). This could explain the partial eddy saturation found in recent studies where nonzero ACC transport sensitivity to wind increase is found (Hallberg and Gnanadesikan 2006; Farneti et al. 2010; Jones et al. 2011; Meredith et al. 2012; Dufour et al. 2012; Morrison and Hogg 2013). Part of the energy imparted by the wind may be used to accelerate the barotropic flow and part of it may feed eddies that dissipate the baroclinic increase in the flow (on time scales of a few years).

Our analysis of the ACC response to wind increases differs from Morrow et al. (2010), where the differences in the amplitude of the EKE response (between the 1993 and 1999 events) are explained using quasigeostrophic (QG) dynamics in the context of a pure eddy saturation regime. The QG model assumes an eddy saturated ocean where the amplification or reduction of EKE is attributed to regional modulations of the wind stress amplitude by ENSO. Lower intensification of wind simply leads to lower EKE amplitude in the response. Based on our analysis of several simulations, we propose instead that the ACC responses correspond to different barotropic and baroclinic mechanisms.

The interplay of SAM and ENSO plays an important role in setting the different wind forcing that leads to different ocean responses. The interplay of SAM and ENSO controls the intensity of the wind stress over the ACC envelope and along $f / H$ contours. ENSO weakly modulates the westerly wind anomalies associated with SAM but has a strong impact on the wind stress around Antarctica. A positive ENSO only weakens the westerlies anomalies associated with SAM over the ACC, and it doubles the wind anomalies close to Antarctica and can shut down the easterlies. The occurrence of a positive or negative ENSO during a positive SAM event then modifies the relative importance between the two wind-forcing terms. The interplay of SAM and ENSO also alters the spatial pattern of wind anomalies and impacts the position of the wind anomalies relative to the ACC, which is important for the location of Ekman pumping anomalies and for the generation of baroclinicity. While the link between the two modes of climate variability and EKE is further suggested by the good correlation between the two (Fig. S1), sensitivity experiments would be required to confirm the link between the meridional position of the wind anomalies and the eddy response.

The modulation of the Southern Ocean westerlies by ENSO is yet to be fully explored in the atmospheric context (Schneider et al. 2012). So far, negative ENSO has only been shown to reinforce westerly winds during positive SAM (L'Heureux and Thompson 2006; Fogt et al. 2011; Schneider et al. 2012). Here, we have shown that the modulation of the westerlies over the ACC is not the only player in the Southern Ocean and that the interplay of SAM and ENSO should be further investigated.

Acknowledgments. The authors acknowledge the funding support of the Australian Government's Cooperative Research Centre (CRC) program through the Antarctic Climate and Ecosystems CRC and the Australian Climate Change Science Program supported by the Australian Department of the Environment, CSIRO, and the Bureau of Meteorology. Clothilde Langlais was supported by a CSIRO Office of the Chief Executive (OCE) Postdoctoral Fellowship. Jan Zika acknowledges the support of the Natural Environment Research Council. This work used simulations performed within the frame of the Bluelink project and DRAKKAR project. DRAKKAR is supported by the Centre National d'Etudes Spatiales (CNES) through the Ocean Surface Topography Science Team (OST/ST), by the Centre National de la Recherche Scientique (CNRS), the Institut National des Sciences de l'Univers (INSU), and the Groupe Mission Mercator Coriolis (GMMC). Bluelink is funded by CSIRO Oceans and Atmosphere Flagship.

\section{REFERENCES}

Barnier, B., and Coauthors, 2007: Eddy-permitting ocean circulation hindcasts of past decades. CLIVAR Exchanges, No. 12, International CLIVAR Project Office, Southampton, United Kingdom, 8-10.

_ , and Coauthors, 2009: Impact of partial steps and momentum advection schemes in a global ocean circulation model at eddypermitting resolution. Ocean Dyn., 56, 543-567, doi:10.1007/ s10236-006-0082-1.

Böning, C. W., A. Dispert, M. Visbeck, S. R. Rintoul, and F. U. Schwarzkopf, 2008: The response of the Antarctic Circumpolar Current to recent climate change. Nat. Geosci., 1, 864869, doi:10.1038/ngeo362.

Brodeau, L., B. Barnier, T. Penduff, and A.-M. Treguier, 2010: An ERA-40 based atmospheric forcing for global ocean circulation models. Ocean Modell., 31, 88-104, doi:10.1016/ j.ocemod.2009.10.005.

Dee, D. P., and Coauthors, 2011: The ERA-Interim reanalysis: Configuration and performance of the data assimilation system. Quart. J. Roy. Meteor. Soc., 137, 553-597, doi:10.1002/ qj. 828 . 
Dufour, C. O., J. Le Sommer, J. D. Zika, M. Gehlen, J. C. Orr, P. Mathiot, and B. Barnier, 2012: Standing and transient eddies in the response of the Southern Ocean meridional overturning to the southern annular mode. J. Climate, 25, 6958-6974, doi:10.1175/ JCLI-D-11-00309.1.

Farneti, R., T. L. Delworth, A. J. Rosati, S. M. Griffies, and F. Zeng, 2010: The role of mesoscale eddies in the rectification of the Southern Ocean response to climate change. J. Phys. Oceanogr., 40, 1539-1557, doi:10.1175/2010JPO4353.1.

Fogt, R. L., D. H. Bromwich, and K. M. Hines, 2011: Understanding the SAM influence on the South Pacific ENSO teleconnection. Climate Dyn., 36, 1555-1576, doi:10.1007/ s00382-010-0905-0.

Fyfe, J. C., and O. A. Saenko, 2006: Simulated changes in the extratropical Southern Hemisphere winds and currents. Geophys. Res. Lett., 33, L06701, doi:10.1029/2005GL025332.

Gent, P. R., and J. C. McWilliams, 1990: Isopycnal mixing in ocean circulation models. J. Phys. Oceanogr., 20, 150-155, doi:10.1175/ 1520-0485(1990)020<0150:IMIOCM > 2.0.CO;2.

—, W. G. Large, and F. O. Bryan, 2001: What sets the mean transport through Drake Passage? J. Geophys. Res., 106, 2693-2712, doi:10.1029/2000JC900036.

Gill, A. E., 1982: Atmosphere-Ocean Dynamics. Academic Press, 662 pp.

Gnanadesikan, A., and R. W. Hallberg, 2000: On the relationship of the circumpolar current to Southern Hemisphere winds in coarseresolution ocean models. J. Phys. Oceanogr., 30, 2013-2034, doi:10.1175/1520-0485(2000)030<2013:OTROTC > 2.0.CO;2.

Griffies, S. M., 2004: Fundamentals of Ocean Climate Models. Princeton University Press, 518 pp.

, and Coauthors, 2009: Coordinated Ocean-Ice Reference Experiments (COREs). Ocean Modell., 26, 1-46, doi:10.1016/ j.ocemod.2008.08.007.

Hall, A., and M. Visbeck, 2002: Synchronous variability in the Southern Hemisphere atmosphere, sea ice, and ocean resulting from the annular mode. J. Climate, 15, 3043-3057, doi:10.1175/ 1520-0442(2002)015<3043:SVITSH $>2.0$.CO;2.

Hallberg, R., and A. Gnanadesikan, 2001: An exploration of the role of transient eddies in determining the transport of a zonally reentrant current. J. Phys. Oceanogr., 31, 3312-3330, doi:10.1175/ 1520-0485(2001)031<3312:AEOTRO > 2.0.CO;2.

- , and -2006 : The role of eddies in determining the structure and response of the wind-driven Southern Hemisphere overturning: Results from the Modelling Eddies in the Southern Ocean (MESO) project. J. Phys. Oceanogr., 36, 2232-2251, doi:10.1175/ JPO2980.1.

Hogg, A. M., M. P. Meredith, J. R. Blundell, and C. Wilson, 2008: Eddy heat flux in the Southern Ocean: Response to variable wind forcing. J. Climate, 21, 608-620, doi:10.1175/2007JCLI1925.1.

Hughes, C. W., M. P. Meredith, and K. J. Heywood, 1999: Wind-driven transport fluctuations through Drake Passage: A southern mode. J. Phys. Oceanogr., 29, 1971-1992, doi:10.1175/ 1520-0485(1999)029<1971:WDTFTD>2.0.CO;2.

Jones, D. C., T. Ito, and N. S. Lovenduski, 2011: The transient response of the Southern Ocean pycnocline to changing atmospheric winds. Geophys. Res. Lett., 38, L15604, doi:10.1029/ 2011 GL048145.

Kallberg, P., A. Simmons, S. Uppala, and M. Fuentes, 2004: The ERA-40 archive. ERA-40 Project Rep. Series 17, 35 pp. [Available online at http://mms.dkrz.de/pdf/klimadaten/projects/ era40/e40Archive.pdf.]

Kang, D., and O. Fringer, 2010: On the calculation of available potential energy in internal wave fields. J. Phys. Oceanogr., 40, 2539-2545, doi:10.1175/2010JPO4497.1.
Langlais, C., S. Rintoul, and A. Schiller, 2011: Variability and mesoscale activity of the southern ocean fronts: Identification of a circumpolar coordinate system. Ocean Modell., 39, 79-96, doi:10.1016/j.ocemod.2011.04.010.

Large, W. G., and S. G. Yeager, 2009: The global climatology of an interannually varying air-sea flux data set. Climate Dyn., 33, 341-364, doi:10.1007/s00382-008-0441-3.

L'Heureux, M., and D. Thompson, 2006: Observed relationships between the El Niño-Southern Oscillation and the extratropical zonal-mean circulation. J. Climate, 19, 276-287, doi:10.1175/JCLI3617.1.

Madec, G., 2008: NEMO ocean engine. Note du Pole de modelisation de l'Institut Pierre-Simon Laplace 27, 217 pp.

Marshall, G. J., 2003: Trends in the southern annular mode from observations and reanalyses. J. Climate, 16, 4134-4143, doi:10.1175/1520-0442(2003)016<4134:TITSAM>2.0.CO;2.

Marshall, J., and T. Radko, 2003: Residual-mean solutions for the Antarctic Circumpolar Current and its associated overturning circulation. J. Phys. Oceanogr., 33, 2341-2354, doi:10.1175/ 1520-0485(2003)033<2341:RSFTAC > 2.0.CO;2.

Meredith, M. P., and A. M. Hogg, 2006: Circumpolar response of Southern Ocean eddy activity to a change in the southern annular mode. Geophys. Res. Lett., 33, L16608, doi:10.1029/2006GL026499.

— , P. L. Woodworth, C. W. Hughes, and V. Stepanov, 2004: Changes in the ocean transport through Drake Passage during the 1980s and 1990s, forced by changes in the southern annular mode. Geophys. Res. Lett., 31, L21305, doi:10.1029/2004GL021169.

- A. C. N. Garabato, A. M. Hogg, and R. Farneti, 2012: Sensitivity of the overturning circulation in the Southern Ocean to decadal changes in wind forcing. J. Climate, 25, 99110, doi:10.1175/2011JCLI4204.1.

Morrison, A. K., and A. M. Hogg, 2013: On the relationship between Southern Ocean overturning and ACC transport. J. Phys. Oceanogr., 43, 140-148, doi:10.1175/JPO-D-12-057.1.

Morrow, R., M. L. Ward, A. M. Hogg, and S. Pasquet, 2010: Eddy response to Southern Ocean climate modes. J. Geophys. Res., 115, C10030, doi:10.1029/2009JC005894.

O'Kane, T., R. Matear, M. Chamberlain, J. Risbey, B. Sloyan, and I. Horenko, 2013: Decadal variability in an OGCM Southern Ocean: Intrinsic modes, forced modes and metastable states. Ocean Modell., 69, 1-21, doi:10.1016/j.ocemod.2013.04.009.

Oke, P. R., and D. A. Griffin, 2011: The cold-core eddy and strong upwelling off the coast of New South Wales in early 2007. Deep-Sea Res. II, 58, 574-591, doi:10.1016/j.dsr2.2010.06.006.

—, G. B. Brassington, D. A. Griffin, and A. Schiller, 2008: The Bluelink Ocean Data Assimilation System (BODAS). Ocean Modell., 21, 46-70, doi:10.1016/j.ocemod.2007.11.002.

— resolving model. Geosci. Model Dev., 6, 591-615, doi:10.5194/ gmd-6-591-2013.

Olbers, D., and M. Visbeck, 2005: A model of the zonally averaged stratification and overturning in the Southern Ocean. J. Phys. Oceanogr., 35, 1190-1205, doi:10.1175/JPO2750.1.

—, D. Borowski, C. Volker, and J.-O. Wolff, 2004: The dynamical balance, transport and circulation of the Antarctic Circumpolar Current. Antarct. Sci., 16, 439-470, doi:10.1017/ S0954102004002251.

Penduff, T., J. Le Sommer, B. Barnier, A.-M. Treguier, J.-M. Molines, and G. Madec, 2007: Influence of numerical schemes on current-topography interactions in 1/4 global ocean simulations. Ocean Sci., 3, 509-524, doi:10.5194/os-3-509-2007.

-, M. Juza, L. Brodeau, G. C. Smith, B. Barnier, J.-M. Molines, A.-M. Treguier, and G. Madec, 2010: Impact of global ocean 
model resolution on sea-level variability with emphasis on interannual time scales. Ocean Sci., 6, 269-284, doi:10.5194/ os-6-269-2010.

Rintoul, S. R., and A. C. Naveira Garabato, 2013: Dynamics of the Southern Ocean. Ocean Circulation and Climate: A 21st Century Perspective, G. Siedler et al., Eds., International Geophysics Series, Vol. 103, Academic Press, 471-492.

— C. Hughes, and D. Olbers, 2001: The Antarctic Circumpolar Current system. Ocean Circulation and Climate: Observing and Modelling the Global Ocean, G. Siedler, J. Church, and J. Gould, Eds., International Geophysics Series, Vol. 77, Academic Press, 271-302.

Saenko, O. A., 2007: Projected strengthening of the Southern Ocean winds: Some implications for the deep ocean circulation. Ocean Circulation: Mechanisms and Impacts, Geophys. Monogr., Vol. 173, Amer. Geophys. Union, 365382.

_ J. C. Fyfe, and M. H. England, 2005: On the response of the oceanic wind-driven circulation to atmospheric $\mathrm{CO}_{2}$ increase. Climate Dyn., 25, 415-426, doi:10.1007/s00382-005-0032-5.

Sallée, J. B., K. Speer, and R. Morrow, 2008: Response of the Antarctic Circumpolar Current to atmospheric variability. J. Climate, 21, 3020-3039, doi:10.1175/2007JCLI1702.1.

Schiller, A., P. R. Oke, G. B. Brassington, M. Entel, R. Fiedler, D. A. Griffin, and J. V. Mansbridge, 2008: Eddy-resolving ocean circulation in the Asian-Australian region inferred from an ocean reanalysis effort. Prog. Oceanogr., 76, 334-365, doi:10.1016/j.pocean.2008.01.003.

Schneider, D. P., Y. Okumura, and C. Deser, 2012: Observed Antarctic interannual climate variability and tropical linkages. J. Climate, 25, 4048-4066, doi:10.1175/JCLI-D-11-00273.1.

Screen, J. A., N. P. Gillett, D. P. Stevens, G. J. Marshall, and H. K. Roscoe, 2009: The role of eddies in the Southern Ocean temperature response to the southern annular mode. $\mathrm{J}$. Climate, 22, 806-818, doi:10.1175/2008JCLI2416.1.
Sen Gupta, A., and M. H. England, 2007: Coupled oceanatmosphere feedback in the southern annular mode. J. Climate, 20, 3677-3692, doi:10.1175/JCLI4200.1.

Stevens, D. P., and V. O. Ivchenko, 1997: The zonal momentum balance in an eddy resolving general circulation model of the Southern Ocean. Quart. J. Roy. Meteor. Soc., 123, 929-951, doi:10.1002/qj.49712354008.

Straub, D. N., 1993: On the transport and angular momentum balance of channel models of the Antarctic Circumpolar Current. J. Phys. Oceanogr., 23, 776-782, doi:10.1175/ 1520-0485(1993)023<0776:OTTAAM >2.0.CO;2.

Tansley, C. E., and D. P. Marshall, 2001: On the dynamics of winddriven circumpolar currents. J. Phys. Oceanogr., 31, 3258-3273, doi:10.1175/1520-0485(2001)031<3258:OTDOWD>2.0.CO;2.

Thompson, D. W. J., and S. Solomon, 2002: Interpretation of recent Southern Hemisphere climate change. Science, 296, 895-899, doi:10.1126/science.1069270.

Treguier, A. M., M. H. England, S. R. Rintoul, G. Madec, J. Le Sommer, and J.-M. Molines, 2007: Southern Ocean overturning across streamlines in an eddying simulation of the Antarctic Circumpolar Current. Ocean Sci., 3, 491-507, doi: 10.5194/os-3-491-2007.

— J. Le Sommer, J. M. Molines, and B. de Cuevas, 2010: Response of the Southern Ocean to the southern annular mode: Interannual variability and multidecadal trend. J. Phys. Oceanogr., 40, 1659-1668, doi:10.1175/2010JPO4364.1.

Webb, D. J., and B. A. de Cuevas, 2007: On the fast response of the Southern Ocean to changes in the zonal wind. Ocean Sci., 3, 417-427, doi:10.5194/os-3-417-2007.

Zika, J. D., and Coauthors, 2013a: Vertical eddy fluxes in the Southern Ocean. J. Phys. Oceanogr., 43, 941-955, doi:10.1175/ JPO-D-12-0178.1.

, J. Le Sommer, C. O. Dufour, A. Naveira-Garabato, and A. Blaker, 2013b: Acceleration of the Antarctic Circumpolar Current by wind stress along the coast of Antarctica. J. Phys. Oceanogr., 43, 2772-2784, doi:10.1175/JPO-D-13-091.1. 